\title{
INVESTIGATIONS ON THE MECHANISM OF THE LEUKOPENIC RESPONSE TO SHIGELLA ENDOTOXIN ${ }^{1}$
}

\author{
BY WILLIAM D. DONALD, CHARLES H. WINKLER, AND KENDRICK HARE \\ (From the Departments of Pediatrics and Microbiology, University of Alabama Medical \\ College, Birmingham, Ala.)
}

(Submitted for publication February 17, 1958; accepted March 27, 1958)

A marked leukopenia, followed usually by a leukocytosis, is one of the constant reactions produced in experimental animals by the administration of endotoxin from Gram-negative bacilli. This reaction occurs along with other disturbances including fever, shock, hyperglycemia followed by hypoglycemia, thrombocytopenia and pathological changes in the gastrointestinal tract. The leukopenic response which has been described by many investigators (1-3) has been confirmed in this laboratory by our observations on dogs following the intravenous injection of Shigella endotoxin. We have also noted a rather marked leukopenia in some children with gastroenteritis due to Shigella (4).

In 1952, Penner and Klein (5) presented evidence that certain systemic effects, including the leukopenic response, following the intravenous injection of Shigella dysenteriae endotoxin are mediated by the direct action of this toxin on the central nervous system. From the results of cerebral cross-circulation experiments in which one of a pair of dogs received the entire blood supply to his brain from his partner, and vice versa, they reported that only the $\operatorname{dog}$ whose brain received its blood supply from the opposite dog, into whom the toxin had been injected, developed leukopenia and other systemic changes. The dog into which the toxin was injected failed to manifest the typical disturbances. They concluded from these experiments that the toxin acts directly on the brain, and suggested that the site of action was probably in the region of the hypothalamus.

Weil, MacLean, Spink, and Visscher (6) have recently presented evidence that does not support the idea that the shock produced by endotoxin is a result of a direct action on the central nervous system. They found that in cross-circulation ex-

1 This investigation was supported by Grant No. E-1233 from the National Institutes of Health, Public Health Service, Department of Health, Education and Welfare. periments as described by Penner and Klein the shock and the leukopenia was not limited to the dog whose brain received the endotoxin. They further report that the shock is produced by endotoxin in dogs on whom chordotomy, with and without vagotomy, has been performed; and that arterial hypotension occurs in the decapitated dog given endotoxin.

The work of Mitchell and Stuart (7) on adrenalectomized cats suggests that the leukopenic response to Pyromen ${ }^{\circledR}$ is mediated through the adrenal gland. Soylemezoglu and Wells $(8,9)$, however, reported that the typical leukopenic response is obtained following the intravenous administration of pyrogen to adrenalectomized dogs.

The data to be presented here are the results of experiments designed to investigate the possible mechanisms of the leukopenic response to Shigella endotoxin with reference to the central nervous system and the adrenal gland.

\section{MATERIAL AND METHODS}

Endotoxin. "Crude endotoxin" was prepared from a culture of $S$. flexneri (type 2a) isolated from a patient with diarrhea in the pediatric ward of the University Hospital, and from a culture of $S$. dysenteriae (strain $\mathrm{D}_{2}$ ) obtained from Dr. Sarah Branham (National Institutes of Health, Bethesda, Md). The toxins prepared from these two cultures are referred to as " $\mathrm{J}$ " toxin and " $\mathrm{D}_{2}$ " toxin, respectively. The "crude endotoxin" was prepared in the following manner: The bacteria were inoculated on brain heart infusion agar in Roux bottles and the growth harvested after 18 to 24 hours incubation by washing with normal saline. The growth from three bottles was then washed three times by centrifugation with normal saline and the sedimented cells were ground in a mortar for 30 minutes with alundum. Normal saline was added to make the total volume $100 \mathrm{ml}$. The suspension was centrifuged and the supernate was filtered (Seitz). The resulting filtrate constituted the "crude endotoxin" hereafter referred to as "toxin." It was not standardized, but by a series of trials it was found that the desired leukopenic response and the gastrointestinal lesions were invariably produced in dogs when $1 \mathrm{ml}$. per 
kilogram of body weight was given intravenously. This dose was actually far in excess of the amount required to produce the typical responses but was used routinely unless otherwise stated.

The toxin was injected into either the femoral or brachial vein of both anesthetized (Nembutal ${ }^{\circledR}$ ) and unanesthetized normal adult dogs, and blood samples were collected from either the femoral or brachial vein. The samples were collected in tubes to which a few heparin crystals had been added as an anticoagulant. White blood counts were performed in the conventional manner on a Spencer Bright Line counting chamber, using N/10 hydrochloric acid as the diluting fluid.

Cerebral cross-circulation was performed by the method described by Penner and Klein with the following modifications: The vertebral vessels were exposed by way of a low, anterior, mid-line, longitudinal, cervical incision and ligated before their entrance into the vertebral canal of the transverse process. The entire procedure of ligation of the vertebral vessels, cross-circulation and administration of the toxin, was done at one time, rather than the preliminary ligation of the vertebral vessels as described by Penner and Klein. With these exceptions, the procedure described by the above mentioned investigators was used. In two experiments human serum albumin labeled with radioactive phosphorus $\left(\mathrm{P}^{32}\right)$ was injected into Dog 1 at the same time as the toxin and radioactivity were measured in blood samples from both dogs at various intervals. A deep well counter was employed for these counts. A fall in temperature in the animals was prevented by the application of external heat, since it has been shown that a leukopenia will develop in dogs made hypothermic $(10,11)$.

Decapitation was performed at the level of the sixth cervical vertebra. Artificial respiration was maintained by means of a Stoelting respiration pump, and a fall in body temperature was prevented as above. Toxin was administered intravenously, and blood specimens were obtained at regular intervals.

Bilateral adrenalectomy was performed in a one stage
TABLE I

Leukopenic response to Shigella toxin in normal dogs

\begin{tabular}{lrrrrr}
\hline \hline & \multicolumn{2}{c}{ Unanesthetized } & & \multicolumn{2}{c}{ Anesthetized } \\
\cline { 2 - 3 } \cline { 5 - 6 } Time & Dog 1 & Dog 2 & & Dog 3 & Dog 4 \\
\hline 0 hour & 10,300 & 5,500 & & 15,000 & 10,000 \\
1 hour & 1,250 & 1,000 & & 2,100 & 1,950 \\
2 hours & 1,200 & 3,300 & & 2,900 & 5,000 \\
3 hours & 2,500 & 7,900 & & 9,000 & 6,050 \\
4 hours & 5,500 & 8,750 & & 16,000 & 12,400 \\
5 hours & 10,060 & 20,750 & & 15,000 & 19,200
\end{tabular}

procedure through a right subcostal incision. The adrenalectomized dogs were given $75 \mathrm{mg}$. of cortisone acetate (11 dehydro-17 hydroxycorticosterone-21 acetate) intramuscularly 24 hours prior to surgery and were maintained on this daily intramuscular dose until able to take the medication in oral form. They were then given a single daily dose of $75 \mathrm{mg}$. with additional sodium chloride in their drinking water for a period of 10 to 15 days following surgery. Twenty-four hours prior to the administration of the toxin oral cortisone acetate was omitted, and the animals received $25 \mathrm{mg}$. of the intramuscular preparation at this time. The animals appeared to be in good condition at the time of toxin administration but were in mild adrenal insufficiency as evidenced by altered serum electrolytes.

\section{RESULTS}

\section{Normal dogs}

In Table I the white blood counts in normal dogs, following the injection of Shigella toxin, are presented as examples of the leukopenic response. It will be noted that anesthesia did not alter this response. This typical leukopenia is a constant reaction to endotoxins.

TABLE II

White blood counts and radioactivity in cross-circulation dogs

\begin{tabular}{|c|c|c|c|c|c|c|c|c|c|c|c|c|}
\hline \multirow[b]{3}{*}{ Time } & \multirow{2}{*}{\multicolumn{2}{|c|}{$\begin{array}{c}\text { Experiment I } \\
\text { W.B.C. }\end{array}$}} & \multirow{2}{*}{\multicolumn{2}{|c|}{$\begin{array}{c}\text { Experiment II } \\
\text { W.B.C. }\end{array}$}} & \multicolumn{4}{|c|}{ Experiment III } & \multicolumn{4}{|c|}{ Experiment IV } \\
\hline & & & & & \multicolumn{2}{|c|}{ w.B.c. } & \multicolumn{2}{|c|}{ Counts/min. } & \multicolumn{2}{|c|}{ W.B.c. } & \multicolumn{2}{|c|}{ Counts/min. } \\
\hline & $\operatorname{Dog} 1$ & Dog 2 & Dog 1 & $\operatorname{Dog} 2$ & Dog 1 & Dog 2 & Dog 1 & Dog 2 & $\operatorname{Dog} 1$ & Dog 2 & Dog 1 & $\operatorname{Dog} 2$ \\
\hline $\begin{array}{l}\text { After cross- } \\
\text { circulation } \\
0 \text { hour }\end{array}$ & 19,000 & 12,400 & $\begin{array}{c}13,100 \\
\text { oxin into }\end{array}$ & $\begin{array}{l}10,000 \\
\text { Dog } 1\end{array}$ & 10,500 & 6,050 & xin an & radi & $\begin{array}{l}12,500 \\
\text { ctive alb }\end{array}$ & $\begin{array}{l}13,000 \\
\text { dmin int }\end{array}$ & Dog 1 & \\
\hline $\begin{array}{l}5 \mathrm{~min} . \\
30 \mathrm{~min} . \\
60 \mathrm{~min} . \\
80 \mathrm{~min} .\end{array}$ & $\begin{array}{l}3,100 \\
3,600 \\
3,300\end{array}$ & $\begin{array}{l}7,000 \\
4,800 \\
2,250\end{array}$ & $\begin{array}{l}2,200 \\
2,300\end{array}$ & $\begin{array}{l}2,200 \\
1,350\end{array}$ & $\begin{array}{l}6,300 \\
2,200\end{array}$ & $\begin{array}{l}3,800 \\
4,600\end{array}$ & 5,642 & 4,868 & $\begin{array}{l}4,500 \\
4,600\end{array}$ & $\begin{array}{l}7,000 \\
3,000\end{array}$ & $\begin{array}{l}3,045 \\
2,281\end{array}$ & $\begin{array}{r}745 \\
1,537\end{array}$ \\
\hline $\begin{array}{l}90 \mathrm{~min} . \\
120 \mathrm{~min} . \\
150 \mathrm{~min} . \\
180 \mathrm{~min} .\end{array}$ & 4,900 & 2,250 & 4,600 & 3,250 & $\begin{array}{l}6,400 \\
3,800 \\
3,100 \\
9,500\end{array}$ & $\begin{array}{r}9,700 \\
7,000 \\
6,000 \\
18,000\end{array}$ & 4,339 & 3,997 & $\begin{array}{l}4,000 \\
3,800 \\
3,300 \\
3,850\end{array}$ & $\begin{array}{l}3,700 \\
3,300 \\
1,450 \\
9,200\end{array}$ & 1,709 & 1,607 \\
\hline
\end{tabular}


TABLE III

Leukocyte response to Shigella toxin in decapitated dogs

\begin{tabular}{|c|c|c|c|c|c|c|c|c|c|}
\hline \multirow[b]{2}{*}{ Time } & \multicolumn{4}{|c|}{ Controls-no toxin } & \multicolumn{2}{|c|}{ "J" toxin } & \multicolumn{3}{|c|}{$\mathrm{D}_{2}$ toxin } \\
\hline & Dog 1 & $\operatorname{Dog} 2$ & $\operatorname{Dog} 3$ & $\operatorname{Dog} 4$ & Dog 5 & $\operatorname{Dog} 6$ & $\operatorname{Dog} 7$ & Dog 8 & $\operatorname{Dog} 9$ \\
\hline \multirow{9}{*}{$\begin{array}{l}\text { Pre-op. } \\
\text { Post-op. } \\
0 \text { hour } \\
15 \text { min. } \\
30 \text { min. } \\
45 \text { min. } \\
60 \text { min. } \\
75 \text { min. } \\
90 \text { min. } \\
105 \text { min. } \\
120 \text { min. }\end{array}$} & 13,500 & 21,300 & & 15,000 & 13,050 & \multirow{4}{*}{$\begin{array}{r}12,200 \\
\text { Toxin, } \\
5,850 \\
2,400\end{array}$} & 6,050 & \multirow{2}{*}{$\begin{array}{l}13,000 \\
25,000\end{array}$} & \multirow{2}{*}{$\begin{array}{l}14,000 \\
14,450\end{array}$} \\
\hline & 17,250 & 35,000 & 40,250 & 11,000 & 14,500 & & 11,200 & & \\
\hline & 14.800 & 22.000 & \multirow{7}{*}{$\begin{array}{l}33,150 \\
28,850\end{array}$} & 13.200 & 900 & & $\begin{array}{l}\text { ravenously } \\
2,160\end{array}$ & \multirow{7}{*}{$\begin{array}{l}1,700 \\
6,000 \\
1,650 \\
1,400 \\
1,050\end{array}$} & \multirow{7}{*}{$\begin{array}{r}8,000 \\
950 \\
850 \\
1,500\end{array}$} \\
\hline & $\begin{array}{l}14,000 \\
13,700\end{array}$ & 25,000 & & 12,000 & 1,700 & & 2,250 & & \\
\hline & & & & 15,000 & 1,500 & & 2,250 & & \\
\hline & 15,200 & 33,000 & & 17,000 & 1,550 & 6,250 & 2,800 & & \\
\hline & & & & 15,000 & 1,850 & & 2,300 & & \\
\hline & 11,200 & & & 12,000 & 3,000 & & 2,600 & & \\
\hline & 11,900 & & & $\begin{array}{l}14,000 \\
11,800\end{array}$ & $2, \pi$ & 5,000 & $\begin{array}{l}2,000 \\
2,550\end{array}$ & & \\
\hline
\end{tabular}

\section{Cerebral cross-circulation}

The white blood counts in the paired dogs of the cross-circulation experiments are presented in Table II. "J" toxin was used in Experiments I and II and " $\mathrm{D}_{2}$ " toxin in Experiments III and IV. In contrast to the results obtained by Penner and Klein, a definite leukopenia developed in both dogs of each pair. The fact that the desired separation of the circulations in the two dogs was not obtained by the procedure used is obvious on examination of the radioactive counts in the blood samples of the paired dogs in Experiments III and IV. Five minutes after injection of the labeled albumin into Dog 1 in Experiment IV, the activity of the blood in Dog 2 was approximately 24 per cent of the blood from Dog 1; after 30 minutes it was between 65 and 85 per cent. At the end of three hours there was complete equilibration of the radioactive material in the circulations of the two dogs. Postmortem examination of the

TABLE IV

Leukopenic response to Shigella toxin in adrenalectomized dogs

\begin{tabular}{crrrrrr}
\hline \hline Time & Dog 1 & Dog 2 & Dog 3 & Dog 4 & Dog 5 & Dog 6 \\
\hline 0 hour & 17,900 & 12,000 & 11,000 & 42,000 & 30,000 & 19,000 \\
15 min. & 5,300 & 8,200 & 2,850 & & 5,000 & 9,050 \\
30 min. & $*$ & 2,100 & 5,100 & 7,000 & 1,600 & 2,800 \\
45 min. & 1,600 & 2,000 & 4,500 & 2,900 & 2,850 \\
60 min. & 950 & 1,200 & 4,300 & $*$ & 3,850 \\
75 min. & & 10,600 & 6,000 & & 15,050 \\
90 min. & 550 & 9,300 & 8,800 & & 10,700 \\
105 min. & & $*$ & & 7,200 \\
120 min. & 3,000 & & $*$ & & 7,400 \\
135 min. & & & & & 10,000 \\
150 min. & 2,300 & & & & 12,500 \\
165 min. & $*$ & & & & $*$ \\
& & & & & &
\end{tabular}

* Dog expired. gastrointestinal tracts of the paired dogs revealed no differences in the lesions present in the two animals.

\section{Decapitation}

The results of the white blood counts in the decapitated animals are tabulated in Table III. It may be noted that in the control animals no significant leukopenia developed after decapitation. This is in marked contrast to the definite leukopenic response in the decapitated animals which received the toxin. This response is graphically presented in Figure 1 which shows the per cent change in the leukocyte count of the decapitated dogs. In the control animals the greatest fall in the white blood count was 36 per cent, whereas in all the animals which received toxin there was a drop of at least 80 per cent within 30 minutes after the injection of the toxin. As in the previous experiment, toxin from both $S$. flexneri and $S$. dysenteriae was used.

Postmortem examination of the gastrointestinal tracts of the decapitated dogs revealed severe hemorrhagic lesions, indistinguishable both grossly and microscopically in the control and toxin-injected animals.

\section{Adrenalectomy}

The leukocyte response to Shigella toxin in adrenalectomized dogs is shown in Table IV. Again it will be noted that these animals responded to the toxin by the development of a definite leukopenia. The dose of toxin administered to Dog 1 was $0.5 \mathrm{ml}$. per kilogram of body weight, and the animal expired 20 minutes later. Subse- 


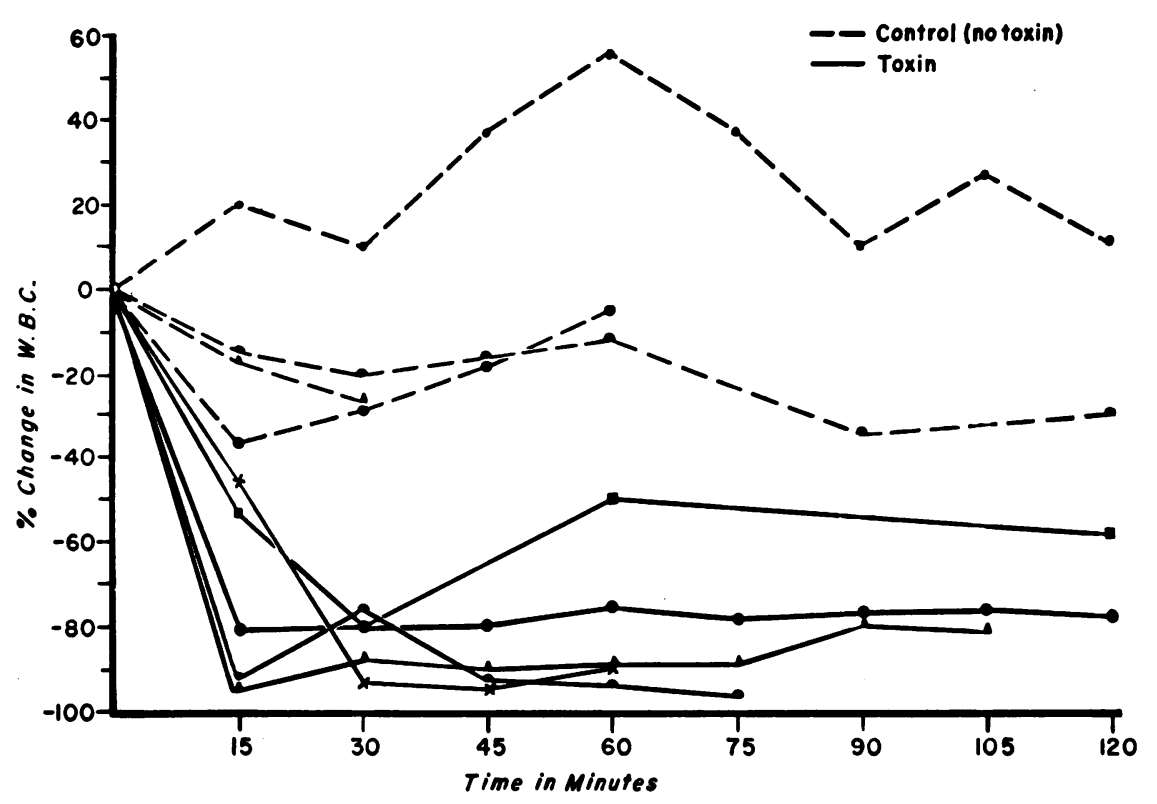

Fig. 1. Per Cent Change in Leukocyte Count in Decapitated Dogs Following the Intravenous Administration of Shigella Toxin

quently, the dose of toxin employed was $0.1 \mathrm{ml}$. per kilogram of body weight, and with this dose death occurred within three hours.

Postmortem examination of the gastrointestinal tracts in these animals revealed hemorrhagic lesions as in the other experiments.

\section{DISCUSSION}

While the results of the cross-circulation experiments presented here are quite different from those of Penner and Klein (5), they are in agreement with the results reported by Weil and coworkers (6). The latter investigators concluded that this technique did not satisfactorily exclude the anastomotic channels in the skin, muscle and within the spinal canal, and, therefore, the endotoxin entered the opposite circulation. They note the fact that the endotoxin used by Penner and Klein was produced from $S$. dysenteriae which is known to differ from other Gram-negative bacilli in that it produces a neurotoxin which acts as an exotoxin. In our experiments this variable was eliminated, since toxin from a culture of $S$. dysenteriae, known to produce a potent neurotoxin, as well as toxin from a culture of $S$. flexneri which does not produce a neurotoxin was used. As in the experiments of Penner and Klein, and Weil and associates, an excess of toxin was employed in our studies.

Although separation of the circulations was not achieved in the cross-circulation experiments, the results of the decapitation studies would exclude the brain as essential for the production of the leukopenic response. The possibility exists that there is more than one mechanism for the production of the leukopenia and that one of these does involve the brain. To disprove this possibility it would be necessary to obtain a satisfactory separation of the two circulations, and this has not been done in the experiments here reported. This problem might be answered in spite of the incomplete separation of the circulation by adjusting the dose of toxin so that the minimum neutropenic quantities of the toxin were injected into Dog 1 . If a leukopenia occurred in Dog 2 under these circumstances it would be expected that the cause was central stimulation. Attempts to establish the desired minimum dose of toxin have been very discouraging due to the rather marked variation of response in individual dogs to small doses of toxin: Although the possibility of a second mechanism which does involve the brain has not been disproved, it is difficult to explain the failure of development of leukopenia in Dog 1 in the experi- 
ments of Penner and Klein in view of the large doses of toxin employed by these investigators.

The studies of Braude, Carey, and Zalesky (12) are of interest in this regard, in that they were unable to detect significant radioactivity in the brains of rabbits which had received $E$. coli endotoxin labeled with radioactive sodium chromate. They did find a large amount of the labeled endotoxin in the buffy coat at the time of the leukopenia.

Chambers, Koenig, Koenig, and Windle (13) have reported a leukopenic response to bacterial pyrogens in the dog after cervical spinal cord transection, and Pásztor, Lissák, and Martin (14) found that the cat, after total sympathectomy, responds to the injection of $E$. coli endotoxin with a leukopenia.

Delaunay (1) has attributed the leukopenic response to endotoxins to the retention of the leukocytes in the capillaries of the lungs, liver and spleen. The ultimate fate of these leukocytesthat is, whether they are destroyed or reintroduced into the circulation-is unknown. The data presented here, it would appear to us, exclude the brain as an essential site of action of the endotoxin in the production of a leukopenia.

No conclusions can be drawn as to the action of Shigella toxin on the central nervous system in the pathogenesis of the gastrointestinal lesions, since the decapitation procedure produced lesions indistinguishable from those resulting from the toxin alone. Keller (15), in 1936, described the production of hemorrhagic lesions in the digestive tract by intracranial trauma.

Thomas (3) has commented on the increased susceptibility of adrenalectomized animals to endotoxin. This fact was confirmed by our observations on adrenalectomized dogs as evidenced by the reduced dose of toxin necessary to produce death. Lewis and Page (16) have reported that adrenal extract and steroids exert a protective power against bacterial toxins in adrenalectomized rats. They found a decrease in the total leukocyte count in adrenalectomized rats two hours after the administration of typhoid vaccine, provided the rats had been maintained on saline alone. If, however, the adrenalectomized animals were treated with adrenal extract or compound $\mathrm{A}$, there was no significant change in the total white blood count at the same period of time following the ad- ministration of the typhoid vaccine. Our observations show that there was no alteration in the leukopenic response to Shigella toxin in the adrenalectomized dogs and thus confirm the findings of Soylemezoglu and Wells $(8,9)$.

\section{SUM MARY}

The leukopenic response to Shigella toxin in the dog has been confirmed. The cerebral crosscirculation studies reported by Penner and Klein (5) have been repeated with some modification in the technique, and a satisfactory isolation of the two circulations was not obtained. The decapitated dog responds to the Shigella toxin with a leukopenia, and therefore, we exclude the brain as an essential site of action of the toxin in this specific response. The adrenalectomized dog also responds to Shigella toxin by the development of a leukopenia.

\section{ACKNOWLEDGMENT}

The authors wish to thank Dr. Thomas Patton for performing the adrenalectomies and for his help and advice on the other surgical procedures performed during the course of this study.

\section{REFERENCES}

1. Delaunay, A. Mise en évidence d'une nouvelle propriété des antigènes glucido-lipidiques: Leur pouvoir leucopénisant. C. R. Soc. biol. (Paris) 1943, 137, 589.

2. Bennett, I. L., Jr., and Beeson, P. B. Properties and biologic effects of bacterial pyrogens. Medicine 1950, 29, 365.

3. Thomas, L. The physiological disturbances produced by endotoxins. Ann. Rev. Physiol. 1954, 16, 467.

4. Donald, W. D. Unpublished data.

5. Penner, A., and Klein, S. H. The pathogenesis of experimental dysentery intoxication. J. exp. Med. 1952, 96, 59.

6. Weil, M. H., MacLean, L. D., Spink, W. W., and Visscher, M. B. Investigations on the role of the central nervous system in shock produced by endotoxin from Gram-negative microorganisms. J. Lab. clin. Med. 1956, 48, 661.

7. Mitchell, S. Q., and Stuart, E. G. Role of adrenal gland in mechanism of leucocyte changes upon administration of Pyromen (abstract). Amer. J. Physiol. 1951, 167, 810.

8. Soylemezoglu, B., and Wells, J. A. Comparison of leucocyte response to ACTH and bacterial pyrogen. Proc. Soc. exp. Biol. (N. Y.) 1951, 77, 43.

9. Soylemezoglu, B., and Wells, J. A. Studies on the mechanism of the leucocyte response to bacterial pyrogen. J. Pharmacol. exp. Ther. 1951, 101, 33. 
10. Villalobos, T. J., Adelson, E., and Barila, T. G. Hematologic changes in hypothermic dogs. Proc. Soc. exp. Biol. (N. Y.) 1955, 89, 192.

11. Helmsworth, J. A., Stiles, W. J., and Elstun, W. Leukopenic and thrombocytopenic effect of hypothermia in dogs. Proc. Soc. exp. Biol. (N. Y) 1955, 90, 474.

12. Braude, A. I., Carey, F. J., and Zalesky, M. Studies with radioactive endotoxin. II. Correlation of physiologic effects with distribution of radioactivity in rabbits injected with lethal doses of $E$. coli endotoxin labelled with radioactive sodium chromate. J. clin. Invest. 1955, 34, 858.

13. Chambers, W. W., Koenig, H., Koenig, R., and
Windle, W. F. Site of action in the central nervous system of a bacterial pyrogen. Amer. J. Physiol. 1949, 159, 209.

14. Pásztor, J., Lissák, K., and Martin, J. Untersuchungen am Blutbild total sympathektomierter Katzen. Naunyn-Schmiedeberg's Arch. exp. Path. Pharmak. 1942, 199, 228.

15. Keller, A. D. Ulceration in the digestive tract of the dog following intracranial procedures. Arch. Path. (Chicago) 1936, 21, 127.

16. Lewis, L. A., and Page, I. H. Studies on the protective power of adrenal extract and steroids against bacterial toxins in adrenalectomized rats. Ann. N. Y. Acad. Sci. 1949, 50, 547. 